\title{
Optimization of Combined Economic Emission Dispatch (CEED) Problems in Electrical Power System with the help of Multi- Objective Artificial Bee Colony Method
}

\author{
Raghvendra Pratap Singh ${ }^{1}$ \\ ${ }^{I}$ (Dep. Of Electrical Engineering, Maharishi University of Information Technology, India)
}

\begin{abstract}
Artificial Bee colony is one of the most efficient optimizing technique introduced so far. Artificial Bee Colony simulates the brilliant behavior honey bee swarm. Considering the environmental impacts that grow from the emission produced by the conventional fuel power plants, the economic dispatch that minimizes only the total fuel cost can no longer be considered as single objective function. The ABC strategy is based on mathematical modelling to solve economic, emission and combined economic \& emission dispatch problems by a single equivalent objective function. In this work $A B C$ is used for large set of numerical test function and the result produced by $A B C$ algorithm are compared with the result obtained by other optimizing techniques like Particle Swarm Optimization, Genetic Algorithm Optimization, etc. Results shows that performance of ABC is better than or similar to other optimizing techniques with the advantage of employing lesser control parameters.
\end{abstract}

Keywords: Artificial Bee Colony algorithm, economic emission dispatch, mathematical modelling, price penalty factor, weighted sum method.

\section{Introduction}

A power system is constructed by using interconnected structures for feeding an electric energy from generator sites to the some areas considering a sharing amount of a total power to meet a load demand at a certain period time of operation. One purpose of this strategy is to reduce the total technical operating cost through the combination various types of power plants. A minimizing cost problem of power system operation can be ex-pressed by using an Economic Load Dispatch (ELD) for obtaining a minimum total fuel cost of generating units. In general, ELD's primary objective is to schedule the committed generating unit outputs to meet a certain load demand at a certain time under some operational constraints [1-3]. Presently, since the public awareness of the environ-mental protection has been increased to reduce atmospheric emissions, the ELD considers pollutant emissions in the air from combustions of fossil fuels at thermal power plants [4]. By considering an Emission Dispatch (EmD), the power system operation has to modify operational strategies of the thermal power plants for reducing pollutants in the air [5]. To avoid complexity problems of both dispatching types for determining solutions with difference targets, ELD and EmD are transformed into single objective function as a Combined Economic and Emission Dispatch (CEED).

Artificial bee colony $(\mathrm{ABC})$ algorithm invented by Karaboga has been proved to be more effective than some conventional biological-inspired algorithms like genetic algorithm (GA), differential evolution (DE) and particle swarm optimization (PSO). But, $\mathrm{ABC}$ is superior at exploration and poor at exploitation. This paper presents a recently developed optimization method, where $\mathrm{ABC}$ algorithm is modified to guide the search of candidate solution towards the global optima.

Swarm intelligence has become a research interest to many research scientists of related fields in recent years. The swarm intelligence is defined as " . . any attempt to design algorithms or distributed problem-solving devices inspired by the collective behaviour of social insect colonies and other animal societies. . ." by Bonabeau et al. [6]. Bonabeau et al. focused their viewpoint on social insects alone, such as termites, bees, wasps as well as different ant species. However, the term swarm is used in a general manner to refer to any restrained collection of interacting agents or individuals. The classical example of a swarm is bees swarming around their hive; nevertheless the metaphor can easily be extended to other systems with a similar architecture. For instance, an ant colony can be thought of as a swarm whose individual agents are ants; a flock of birds is a swarm of birds; an immune system [7] is a swarm of cells as well as a crowd is a swarm of people [8]. A few models have been developed to model the intelligent behaviours of honeybee swarms and applied for solving combinatorial type problems [9-16]. There is only one numerical optimization algorithm in the literature based on intelligent behaviour of honeybee swarms [17]. Yang developed a virtual bee algorithm (VBA) [17] to solve the numerical optimization problems. VBA has been introduced to optimize only the functions with two parameters. In VBA, a swarm of virtual bees are generated and started to move randomly in the phase space. These bees interact when they find some target nectar corresponding to the encoded values of the function. The solution for the optimization problem can be obtained from the intensity of bee interactions. For optimizing 
multivariable numerical functions, Karaboga has described a bee swarm algorithm called artificial bee colony (ABC) algorithm [18], which is different from the virtual bee algorithm. The Bees Algorithm is a newly developed population-based optimisation algorithm which has been verified in many fields. However, it is limited to solving single optimisation problems. To apply the Bees Algorithm to a Multi- Objective Optimisation Problem, either the problem is converted to single objective optimisation or the Bees Algorithm modified to function as a Multi-Objective solver.

A novel computation of evolutionary methods is an Artificial Bee Colony (ABC) algorithm. This method was proposed by Karaboga in 2005 based on foraging behaviors of honeybees in nature [20]. This algorithm has abilities to overcome difficulties of evolutionary methods for solving real problems with multidimensional spaces and reducing time of computation [19-21]. These points are covered by using bee's interaction on the gathering and sharing information during searching the best solution. The $\mathrm{ABC}$ also has a powerful computation contrasted to other evolutionary methods, an ability to get out of a local and a global minimum, a capability of handling complex problems, and an effectiveness for solving optimizing problems $[4$, $6,22,23]$.

This paper presents the $\mathrm{ABC}$ for obtaining the best solution of the CEED problems. The objective function of the CEED is subjected to some operational constraints. In these works, IEEE-30 bus system is adopted as a sample system for the simulations.

\section{Problem Statement And Formulation}

A problem of ELD is related to a nonlinear equation. The ELD's objective function is expressed by a total cost for providing a total power from generation stations and it can be computed by using equation. Presently, an ELD includes a pollutant emission as a constraint. Various pollutants have been come from the burning of fossil/conventional fuels in the thermal power plants. The total pollutant emission is formulated by equations the EmD. The ELD and EmD are composed into single objective function of CEED problem with considering a price penalty and a weighted sum factor as a compromised factor as formed in equation. The penalty factor shows the rate coefficient of each generating unit at its maximum output for the given load. The compromised factor shows a sharing contribution of ELD and EmD. Several limitations for performing CEED are given by equation. Specifically, a total transmission loss is not constant and it depends on the power outputs of generating units. The transmission loss can be appeared from a load flow analysis. In general, the CEED problem can be formulated by using expressions as follows:

\subsection{Objective Function}

The EEDP for power generation requires the simultaneous achievement of two objectives:

\subsubsection{Fuel Cost Objective}

The requirement is to minimize the total fuel cost while satisfying the total demand. The equation used to determine the optimal combination for this problem is

$$
F_{c}=\sum_{i=1}^{N}\left(a_{i}+b_{i} * P_{G i}+c_{i} * P_{G i}^{2}\right)
$$

Where:-

$\mathrm{f}$ : total fuel cost $(\$ / \mathrm{hr})$,

ai, bi, ci : fuel cost coefficients of generator

$\mathrm{P}_{\mathrm{Gi}}$ : power output by generator

$\mathrm{n}:$ number of generator

\subsubsection{NOx Emission Objective}

This objective is necessary to minimize the total NOx emission. The total NOx emission created by burning fossil fuels is expressed as:

$$
\boldsymbol{F}_{\boldsymbol{e}}=\sum_{I=1}^{N}\left(\boldsymbol{a}_{i N}+\boldsymbol{b}_{i N} * \boldsymbol{P}_{G i}+\boldsymbol{c}_{i V} * \boldsymbol{P}_{G i}^{2}+d_{i N} * \exp \left(\boldsymbol{e}_{i N} * \boldsymbol{P}_{G i}\right)\right) \boldsymbol{k g} / \mathbf{h r}
$$

Where:-

Fe: total NOx emission $(\mathrm{kg} / \mathrm{hr})$,

$\mathrm{a}_{\mathrm{iN}}, \mathrm{b}_{\mathrm{iN}}, \mathrm{c}_{\mathrm{iN}}, \mathrm{d}_{\mathrm{iN}}$, and $\mathrm{e}_{\mathrm{iN}}$ are NOx coefficients of the $\mathrm{I}^{\text {th }}$ generator emission characteristics.

\subsection{Constraints}

Two constraints need to be satisfied: 


\subsubsection{Power Balance Constraint}

The total power generated must supply the total load demand plus the transmission losses expressed as:

$\sum_{\boldsymbol{i}=1}^{\boldsymbol{n}} \boldsymbol{P g} \boldsymbol{i}=\boldsymbol{P}_{d}+\boldsymbol{P}_{\boldsymbol{i}}$

Where

Pd : total load demand and

$\mathrm{Pl}$ : transmission losses.

For this work, $\mathrm{Pl}$ was assumed to be 0 .

\subsubsection{Generation Limits Constraint}

The power generated $\mathrm{P}$ a by each generator is constrained between its minimum and maximum limits stated as:

$$
\boldsymbol{P}_{\text {Gi min }} \leq \boldsymbol{P}_{G i} \leq \boldsymbol{P}_{\text {Gi } \max }
$$

where

$\mathrm{P}_{\text {Girmn }}$ : minimum power generated by generator

$\mathbf{P}_{\text {Gimax }}$ : maximum power generated by generator

2.2.3 The Transmission Losses

$\boldsymbol{P}_{I}=\sum_{i=1}^{N} \sum_{j=1}^{N}\left(r_{i} / v_{i} v_{j}\right) \cos \left(\delta_{i}-\delta_{j}\right)\left(\boldsymbol{P}_{i} \boldsymbol{P}_{f}+Q_{i} \boldsymbol{Q}_{f}\right)+\left(\boldsymbol{r}_{i} / v_{i} v_{j}\right) \sin \left(\delta_{i}-\delta_{f}\right)\left(\boldsymbol{Q}_{i} \boldsymbol{P}_{f}+\boldsymbol{P}_{i} \boldsymbol{Q}_{f}\right)$

Where

$\mathrm{N}$ : number of buses

$\mathrm{r}_{\mathrm{ij}}$ : series resistance connecting buses $\mathrm{i}$ and $\mathrm{j}$

$\mathrm{Vi}$ : voltage magnitude at bus $\mathrm{i}$

$\delta i$ : voltage angle at bus $\mathrm{i}$

$\mathrm{Pi}$ : real power injection at bus $\mathrm{i}$

Qi : reactive power injection at bus $i$

\subsection{Multi-Objective Formulation}

The Multi-Objective Environmental/Economic Dispatch optimization problem is therefore formulated as:

Minimize $\{\mathrm{fc}, \mathrm{fe}\}$, subject to:

$\sum_{i=1}^{n} \boldsymbol{P g i}=\boldsymbol{P}_{d}$

(power balance), and

$\boldsymbol{P}_{G i \min } \leq \boldsymbol{P}_{G i} \leq \boldsymbol{P}_{G i ̈ \max } \quad$ (generation limits)

\section{An Overview On Foraging Behavior Of Honey Bees}

The minimal model of forage selection that lead to the emergence of collective intelligence of honey bee swarms consists of three essential components: food sources, employed foragers and unemployed foragers, and defines two leading modes of the behavior:

- Recruitment to a nectar source and abandonment of a source.

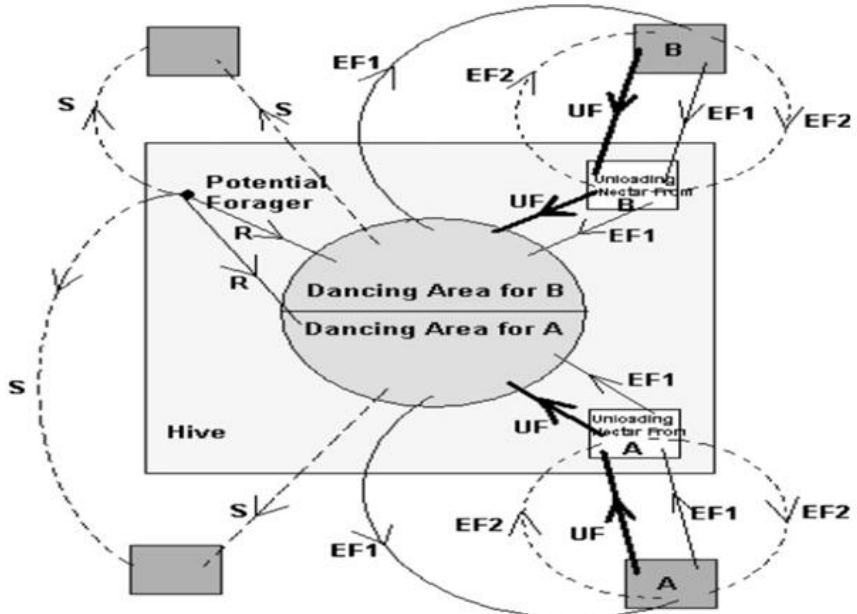

Fig.1 behavior of honeybee foraging for nectar 
Optimization of Combined Economic Emission Dispatch (CEED) Problems in Electrical Power..

(i) Food sources: the value of a food source depends on many factors, such as its proximity to the nest, richness or concentration of energy and the ease of extracting this energy. For the simplicity, the "profitability" of a food source can be represented with a single quantity.

(ii) Employed foragers: they are associated with a particular food source, which they are currently exploiting or are "employed" at. They carry with them information about this particular source, its distance and direction from the nest and the profitability of the source and share this information with a certain probability.

(iii) Unemployed foragers: they are looking for a food source to exploit. There are two types of unemployed foragers - scouts searching the environment surrounding the nest for new food sources and onlookers waiting in the nest and finding a food source through the information shared by employed foragers. The mean number of scouts averaged over conditions is about $5-10 \%$.

\subsection{Proposed Artificial Bee Colony (ABC) algorithm}

In the $\mathrm{ABC}$ algorithm, the colony of artificial bees contains three groups of bees: employed bees, onlookers and scouts. A bee waiting on the dance area for making decision to choose a food source, is called an onlooker and a bee going to the food source visited by itself previously is named an employed bee. A bee carrying out random search is called a scout. In the $\mathrm{ABC}$ algorithm, first half of the colony consists of employed artificial bees and the second half constitutes the onlookers. For every food source, there is only one employed bee. In other words, the number of employed bees is equal to the number of food sources around the hive. The employed bee whose food source is exhausted by the employed and onlooker bees becomes a scout.

The main steps of the algorithm are given below:

- Initialize.

- REPEAT.

(a) Place the employed bees on the food sources in the memory;

(b) Place the onlooker bees on the food sources in the memory;

(c) Send the scouts to the search area for discovering new food sources.

- UNTIL (requirements are met).

\subsection{Artificial Bee Colony flow chart}

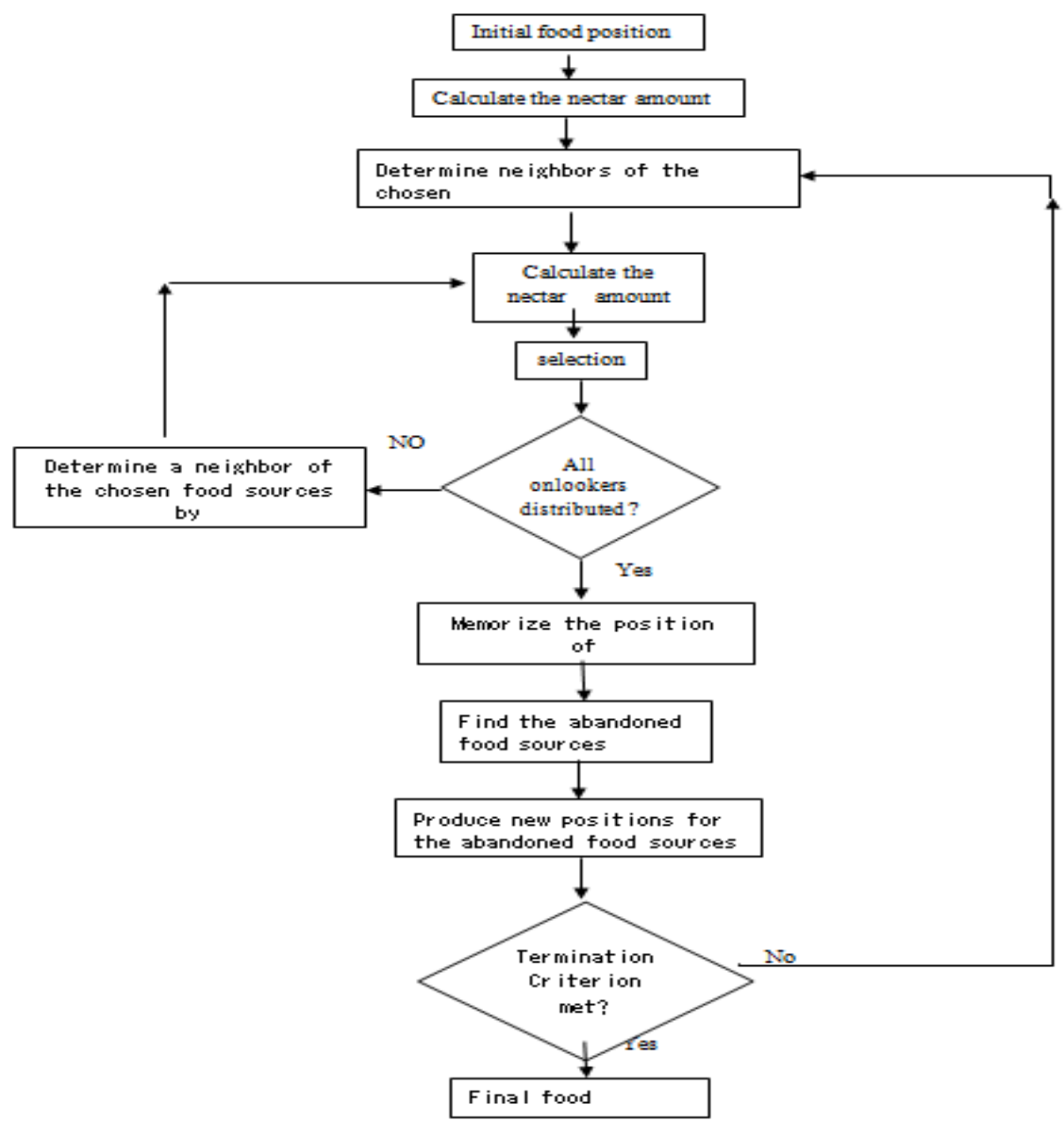

Fig.2 flow chart of ABC method 
The proposed ABC algorithm is tested on standard IEEE-30 bus system with six generating units. All the results shown are for $283.4 \mathrm{MW}$ of load demand. The program of ABC algorithm is implemented on MatLab software version R2011 in a system with 4 GB RAM, Intel i-5 processor with windows 8.

Here the adopted simulation parameters are:-

(1) Colony size $=20$

(2) Limit $=100$

(3) No of iterations $=200$

(4) Load demand $=283.4$

Here we including the term 'Price Penalty Factor' which is represented by the ' $h$ ' and it is given as:-

$\mathrm{h}=$ (Quadratic equation of fuel cost) / (Quadratic equation of gas emission)

and overall combined economic emission dispatch (CEED) can be written as:-

$\mathrm{F}=($ Fuel cost $)+\min (\mathrm{h}) *$ Emission

Table 1 and 2 shows the values of cost and NOx emission coefficients of six generating units. Table 3 shows the loss coefficients of IEEE-30 bus system.

Table 1 Generator costs coefficients

\begin{tabular}{|c|c|c|c|c|c|}
\hline Generator & $\begin{array}{c}\mathrm{a}_{\mathrm{i}} \\
\$ / \mathrm{MW}^{2} \mathrm{hr}\end{array}$ & $\begin{array}{c}\mathrm{b}_{\mathrm{i}} \\
\$ / \mathrm{MWhr}\end{array}$ & $\begin{array}{c}\mathrm{c}_{\mathrm{i}} \\
\$ / \mathrm{hr}\end{array}$ & $\begin{array}{c}\mathrm{P}_{\min } \\
\mathrm{MW}\end{array}$ & $\begin{array}{c}\mathrm{P}_{\max } \\
\mathrm{MW}\end{array}$ \\
\hline $\mathrm{G} 1$ & 0.0037 & 2.0000 & 0 & 50 & 200 \\
\hline $\mathrm{G} 2$ & 0.0157 & 1.7500 & 0 & 20 & 80 \\
\hline $\mathrm{G} 3$ & 0.0625 & 1.0000 & 0 & 15 & 50 \\
\hline $\mathrm{G} 4$ & 0.0083 & 3.2500 & 0 & 10 & 35 \\
\hline $\mathrm{G} 5$ & 0.0250 & 3.0000 & 0 & 10 & 30 \\
\hline G6 & 0.0250 & 3.0000 & 0 & 12 & 40 \\
\hline
\end{tabular}

Table 2 Generator emission coefficients

\begin{tabular}{|c|c|c|c|c|c|}
\hline Generator & $\begin{array}{c}\alpha \\
\mathrm{Kg} / \mathrm{MWhr}^{2}\end{array}$ & $\begin{array}{c}\beta \\
\mathrm{Kg} / \mathrm{MWhr}\end{array}$ & $\begin{array}{c}\gamma \\
\mathrm{Kg} / \mathrm{hr}\end{array}$ & $\begin{array}{c}\mathrm{Q}_{\min } \\
\text { Mvar }\end{array}$ & $\begin{array}{c}\mathrm{Q}_{\max } \\
\text { Mvar }\end{array}$ \\
\hline G1 & 0.0126 & -1.1000 & 22.9830 & 100 & -100 \\
\hline G2 & 0.0200 & -0.1000 & 25.3130 & 60 & -60 \\
\hline G3 & 0.0270 & -0.0100 & 25.5050 & 65 & -15 \\
\hline G4 & 0.0291 & -0.0050 & 24.9000 & 50 & -15 \\
\hline G5 & 0.0290 & -0.0040 & 24.7000 & 40 & -10 \\
\hline G6 & 0.0271 & -0.0055 & 25.3000 & 15 & -15 \\
\hline
\end{tabular}

Table 3 Loss Coefficients for IEEE 30 Bus System (B-matrix)

\begin{tabular}{|l|l|l|l|l|l|}
\hline 0.000218 & 0.000102 & 0.000010 & 0.000010 & 0.000001 & 0.000027 \\
\hline 0.000102 & 0.000187 & 0.000004 & 0.000015 & 0.000003 & 0.000031 \\
\hline 0.000010 & 0.000004 & 0.000430 & 0.000134 & 0.000160 & 0.000108 \\
\hline 0.000010 & 0.000015 & 0.000134 & 0.000097 & 0.000097 & 0.000051 \\
\hline 0.000001 & 0.000003 & 0.000160 & 0.000256 & 0.000256 & 0.000000 \\
\hline 0.000027 & 0.000031 & 0.000108 & 0.000000 & 0.000000 & 0.000359 \\
\hline
\end{tabular}

Table 4 gives the result of comparison between the Evolutionary Programming method and ABC method. In this comparison we can see that the EP method gives the local minimum optimized value whereas proposed $\mathrm{ABC}$ algorithm shows the nature of global minima. Here we can say that we can save $23.22 \$ / \mathrm{hr}$ in fuel cost.

Likewise in table 5, the ABC is compared with PSO method and proposed algorithm is superior to PSO. We saves the $18.56 \$ / \mathrm{hr}$ in fuel cost and $20.59 \mathrm{Kg} / \mathrm{hr}$ of gas emission. The total operating cost is also very low as compare to PSO to $1052 \$ / \mathrm{hr}$.

Table 4 The best solution for fuel cost and emission gas optimized simultaneous for ABC method

\begin{tabular}{|c|c|c|}
\hline $\begin{array}{c}\text { Generator unit } \\
(\mathrm{MW})\end{array}$ & EP method & ABC method \\
\hline P1 & 118.770 & 141.9103 \\
\hline P2 & 62.246 & 50.8288 \\
\hline P3 & 34.462 & 24.3045 \\
\hline P4 & 24.289 & 30.5851 \\
\hline P5 & 21.621 & 21.9017 \\
\hline P6 & 28.072 & 22.0773 \\
\hline Fuel Cost $(\$ / h r)$ & 840.219 & 816.9996 \\
\hline Emission $(\mathrm{Kg} / \mathrm{hr})$ & 350.509 & 356.6430 \\
\hline
\end{tabular}


Optimization of Combined Economic Emission Dispatch (CEED) Problems in Electrical Power..

Table 5 Best optimized values for ABC is compared with PSO method

\begin{tabular}{|c|c|c|c|c|c|}
\hline Method & $\begin{array}{c}\text { Price Penalty Factor - } \mathrm{h} \\
(\$ / \mathrm{kg})\end{array}$ & $\begin{array}{c}\text { Fuel Cost } \\
(\$ / \mathrm{hr})\end{array}$ & $\begin{array}{c}\text { Emission Output } \\
(\mathrm{kg} / \mathrm{hr})\end{array}$ & $\begin{array}{c}\text { Total Operating Cost } \\
(\$ / \mathrm{hr})\end{array}$ & $\begin{array}{c}\text { Total Loss } \\
(\mathrm{MW})\end{array}$ \\
\hline $\mathrm{PSO}$ & 2.3340 & 835.5655 & 377.2407 & 1624 & 5.664 \\
\hline $\mathrm{ABC}$ & 2.3340 & 816.9996 & 356.6430 & 1052.20 & 8.2087 \\
\hline
\end{tabular}

From fig. 3 to 6, the realization of simulation result is been shown. Figures 5.2, 5.3, 5.4 and 5.5 are scaled between no of iterations and objective value, fitness value, fuel cost and emission respectively.

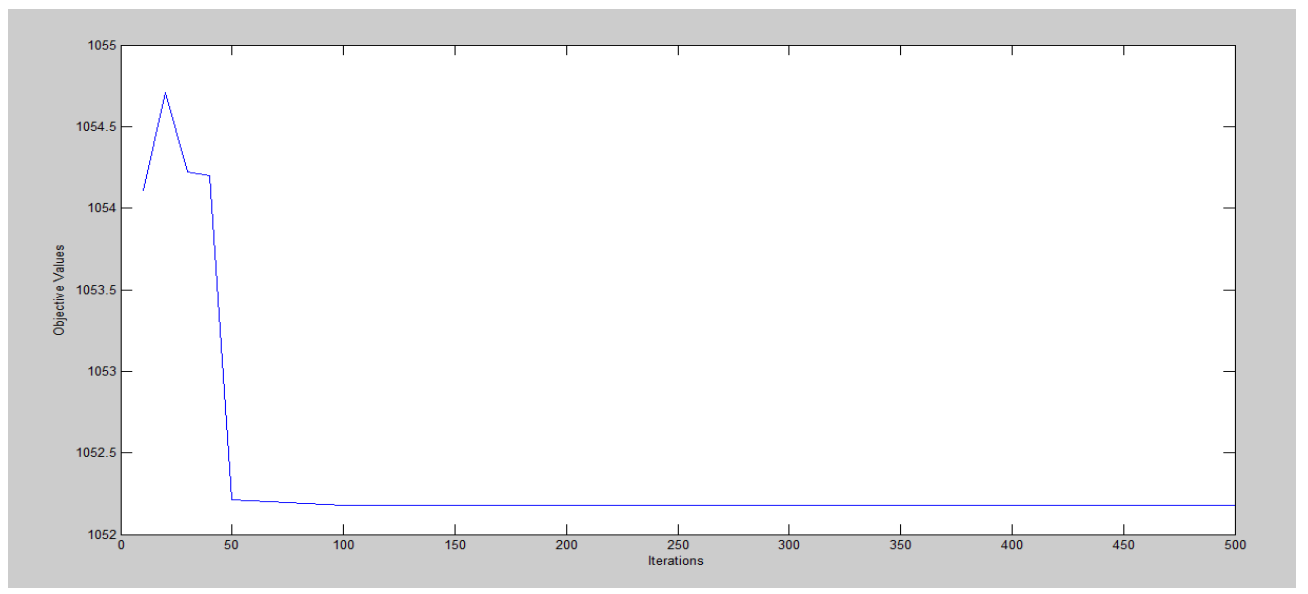

Fig 3 Graph b/t total objective values and no of iteration

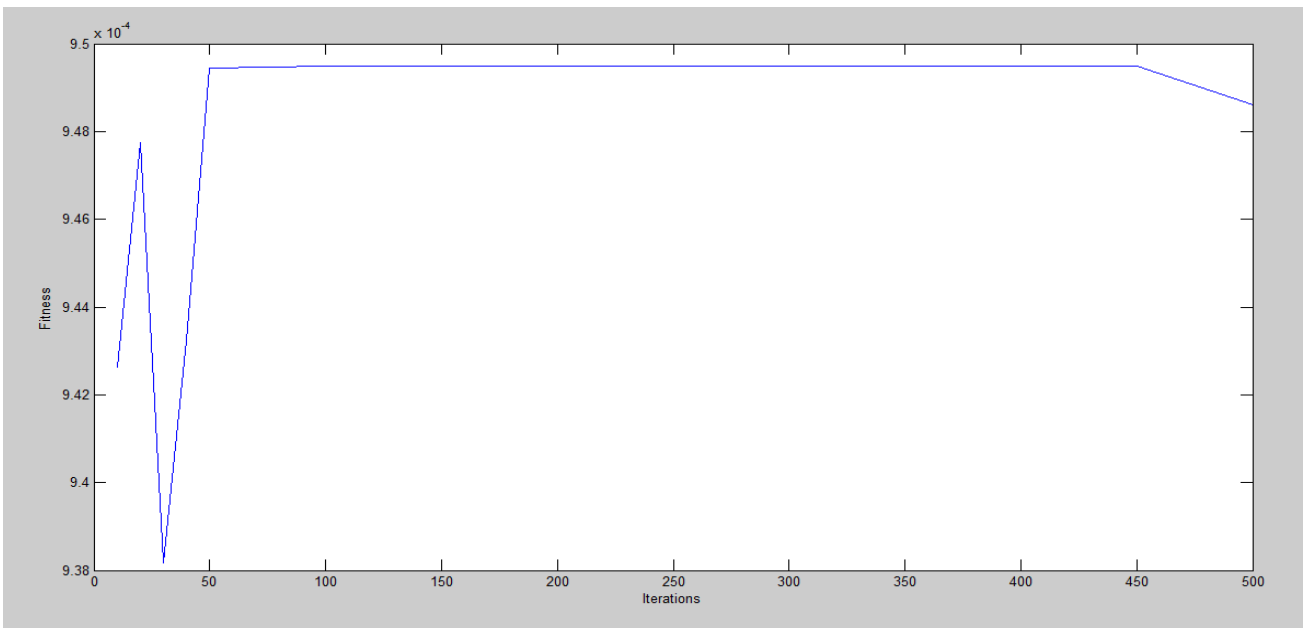

Fig 4 Graph b/t fitness and no of iterations

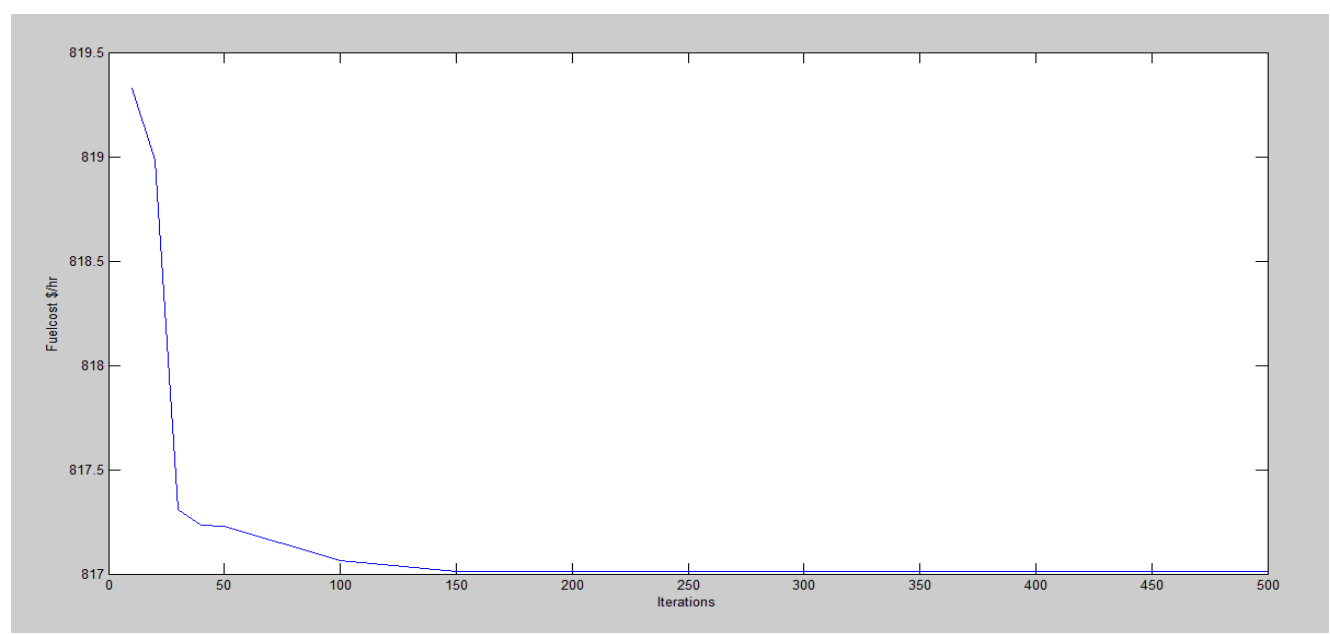

Fig 5 Graph b/t fuel cost and no of iterations 


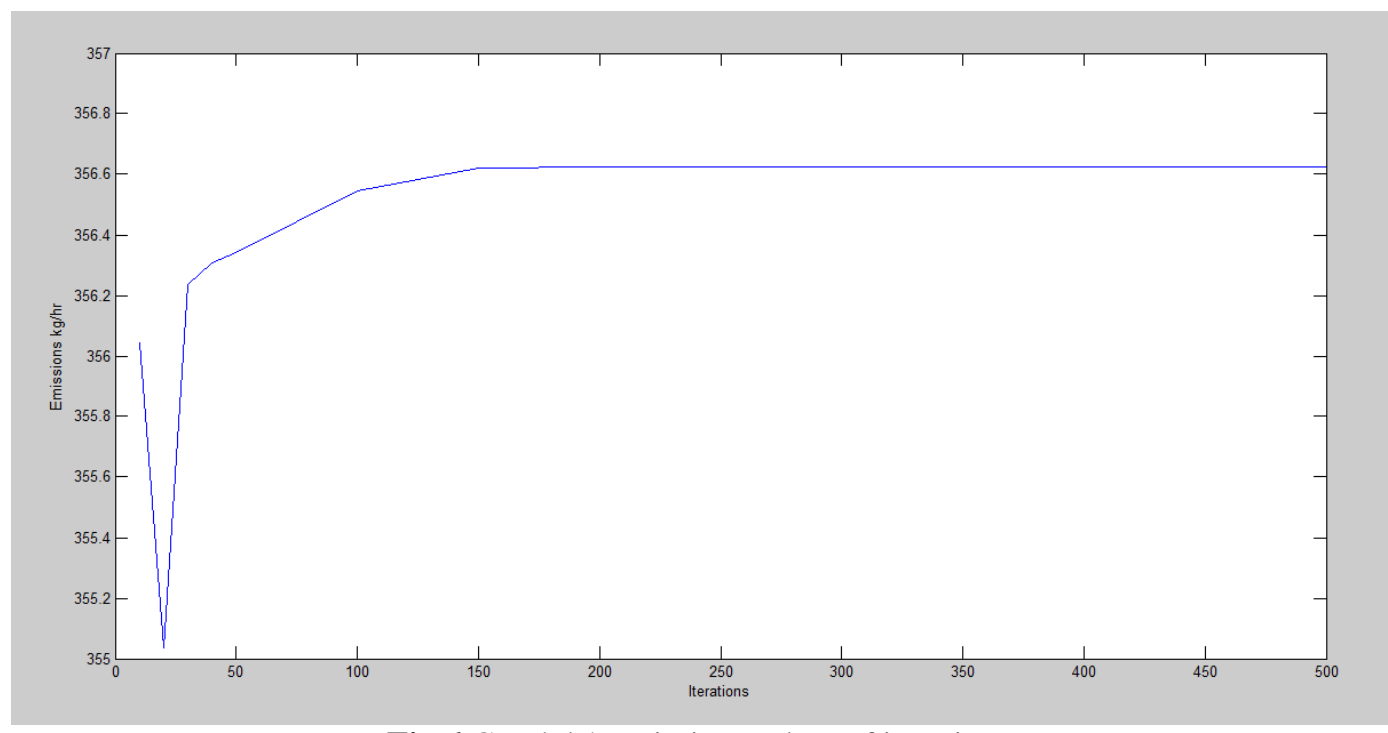

Fig 6 Graph b/t emission and no of iterations

\section{Conclusion}

The application of the ABC method to optimal Power Flow solution to Combined Economic Emission Dispatch Problem is demonstrated in this paper. The test results for the problem shows that in the ABC method, there is only one population, in each iteration, that moves towards the global optimal point, the convergence abilities of the ABC method are better than the evolutionary method and PSO method, the better efficiency and convergence property of the proposed $\mathrm{ABC}$ approach shows that it can be applied to a wide range of optimization problems.

\section{Acknowledgements}

I express my profound sense of gratitude in all its humbleness to my mentor Dr. Geetanjali Mehta, Department of Electrical Engineering, Galgotias University, Noida, India, for his brilliant and gracious guidance and unstinted co-operation throughout my work. I express my profound thanks to Dr. V.K. Yadav and Er. Shahroz Anjum, Department of Electrical Engineering, Galgotias University, Noida, India.

\section{References}

[1]. H. Chahkandi Nejad, 1R. Jahani, 1M. Mohammad Abadi, "GAPSO-based Economic Load Dispatch of Power System", Australian Journal of Basic and Applied Sciences, Vol. 5, No.7, 2011, pp. 606-611.

[2]. M. A. Abido, "Multiobjective Evolutionary Algorithms for Electric Power Dispatch Problem," IEEE Transactions on Evolutionary Computation, Vol. 10, No. 3, 2006, pp. 315-329.

[3]. S. Sayah, K. Zehar, "Economic Load Dispatch with Security Constraints of the Algerian Power System Using Successive Linear Programming Method," Leonardo Journal of Science, No. 9, 2006, pp. 73-86

[4]. Y. Z. Cheng, W. P. Xiao, W.-J. Lee and M. Yang, "A New Approach for Missions and Security Constrained Economic Dispatch", Proc. NAPS, IEEE Conference Publication, Starkville USA, 4-6 Oct 2009, pp. 1-5.

[5]. M. A. Abido, "Environmental/economic Power Dispatch Using Multi objective Evolutionary Algorithm," IEEE Transactions Power Systems, Vol. 18, No. 4, 2003, pp. 1529-1537.

[6]. E. Bonabeau, M. Dorigo, G. Theraulaz, "Swarm Intelligence: From Natural to Artificial Intelligence", NY: Oxford University Press, New York, 1999.

[7]. L.N. De Castro, F.J. Von Zuben, “Artificial Immune Systems, Part I. Basic Theory And Applications", Technical Report No. Rt Dca 01/99, Feec/ Unicamp, Brazil, 1999.

[8]. J. Vesterstrøm, J. Riget, "Particle swarms extensions for improved local, multimodal and dynamic search in numerical optimization”, M.Sc. Thesis, May 2002.

[9]. V. Tereshko, "Reaction-diffusion model of a honeybee colony's foraging behaviour", M. Schoenauer, et al. (Eds.), Parallel Problem Solving from Nature VI, Lecture Notes in Computer Science, vol. 1917, Springer- Verlag, Berlin, 2000, pp. 807-816.

[10]. V. Tereshko, T. Lee, "How information mapping patterns determine foraging behavior of a honey bee colony", Open Syst. Inf. Dyn. 9 (2002) 181-193.

[11]. [11] V. Tereshko, A. Loengarov, "Collective decision-making in honey bee foraging dynamics", Comput. Inf. Syst. J. 1352-94049 (2005).

[12]. D. Teodorovic ${ }^{`}$, "Transport modeling by multi-agent systems: a swarm intelligence approach", Transport. Plann. Technol. 26-4 (August) (2003) 289-312.

[13]. P. Lucic, D. Teodorovic`, "Transportation Modeling: An Artificial Life Approach”, ICTAI, 2002, pp. 216-223.

[14]. D. Teodorovic", M. Dell'orco, "Bee colony optimization - a cooperative learning approach to complex transportation problems", 10th EWGT Meeting, Poznan, 13-16 September, 2005.

[15]. K. Benatchba, L. Admane, M. Koud11, "Using bees to solve data-mining problem expressed as a max-sat one, artificial intelligence and knowledge engineering applications: a bioinspired approach", First International Work-Conference on the Interplay Between Natural and Artificial Computation, IWINAC 2005, Las Palmas, Canary Islands, Spain, June 15-18, 2005. 
[16]. H.F. Wedde, M. Farooq, Y. Zhang, "Bee Hive: an efficient fault-tolerant routing algorithm inspired by honey bee behavior, ant colony, optimization and swarm intelligence", 4th International Workshop, ANTS 2004, Brussels, Belgium, September 5-8, 2004.

[17]. X.S. Yang, "Engineering Optimizations via Nature-Inspired Virtual Bee Algorithms", Lecture Notes in Computer Science, 3562, Springer-Verlag GmbH, 2005,, p. 317.

[18]. Drias, H., Sadeg, S., Yahi, S., "Cooperative bees swarm for solving the maximum weighted satisfiability problem, computational intelligence and bioinspired Systems", Proceedings of the 8th International Workshop on Artificial Neural Networks, IWANN 2005, Vilanovila Geltr, Barcelona, Spain, 8-10 June 2005

[19]. M. Subotic, "Artificial Bee Colony Algorithm for Con-strained Optimization Problems Modified with Multiple Onlookers," International Journal and Mathematical Models and Methods in Applied Sciences, Vol. 6, No. 2, 2012, pp.314-322.

[20]. N. Stanarevic, M. Tuba and N. Bacanin, "Modified Ar-tificial Bee Colony Algorithm for Constrained Problems Optimization", International Journal of Mathematical Models and Methods in Applied Science, Vol. 5, No. 3, 2011, pp. 644-651.

[21]. E. M. Montes, M. D. Araoz and O. C. Dominges, "Smart Flight and Dynamic Tolerances in the Artificial Bee Colony for Constrained Optimization,” Proc. IEEE Congress on Evolutionary Computation CEC , Barcelona, 18-23 July 2010, pp. 1-8.

[22]. D. Karaboga and B. Basturk, "A Powerful and Efficient Algorithm for Numerical Function Optimization: ABC Algorithm,” Journal of Global Optimization, Vol. 39, No. 0925-5001, 2007, pp. 459-471.

[23]. C. C. Columbus and S. P. Simon, "A Parallel ABC for Security Constrained Economic Dispatch Using Shared Memory model," Proc. 2012 EPSCICON IEEE Conference Publication, Thrissur Kerala, 3-6 Jan 2012, pp. 1-6. 